\title{
EL DISCURSO PERSUASIVO EN TEÓCRITO XI
}

\author{
Patricia Mabel Saconi \\ Universidad de Buenos Aires
}

Resumo: 0 presente trabalho apresenta a análise do Itilio XI de Teócrito desde a perspectiva da retórica aplicada a espistola poética, onde Polifemo desenvolve um discurso pronunciado na solidão, convẹtendo-se no destinatário da própria intenção persuasiva.

En el Idilio XI, el rorñús ejemplifica la curación con el canto de la enfermedad producida por Eros en el Cíclope Polifemo. En este Idilio coexisten la dimensión histórica de la creación poética, objetivada en el discurso del roiñńs cuyo destinatario es Nicias ${ }^{1}$, un personajes histórico, y la dimensión del pasado mítico, contemporánea al discurso del Cíclope cuyo destinatario es Galatea, la ninfa amada.

La distribuición de los contenidos se estructura en función de ambạs dimensiones en dos segmentos: el segmento histórico-poético (que abarca los versos 1 a 6 y 80-81) y el segmento mítico (que abarca los versos 7 a 79) donde se ubica el discurso directo de Polifemo.

Dos son las líneas tradicionales, anteriores a Teocrito, que presentan la caracterización de la figura del Cíclope: por un lado, la del canto IX de la Odisea que to presenta como un ser monstruoso y brutal - excepto en las palabras que, una vez cegado por Odiseo, le dirige al carnero (wv. 447-ss.) - por otro, la línea de la composición de Filoxeno ${ }^{2}$ donde Polifemo es un joven sensible y sufre por el amor de Galatea. Teócrito inscribe su personaje en la segunda línea.

Dentro del segmento histórico-poético (vv. 1 a 6), la figura de Eros, caracterizada indirectamente como una fuerza negativa, en tanto que funciona

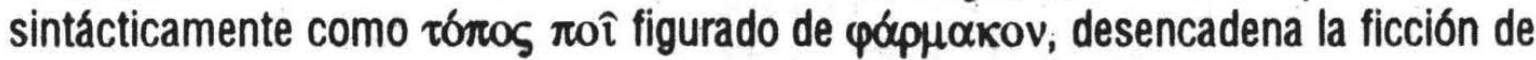

1. Los escolios al Idilio XI contienen los datos relativos a Nicias y la fuente de donde son tomados:

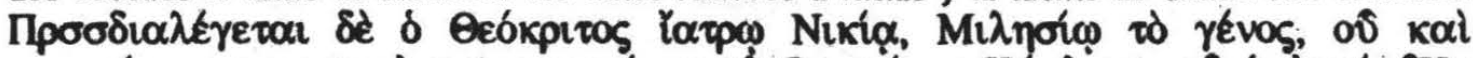

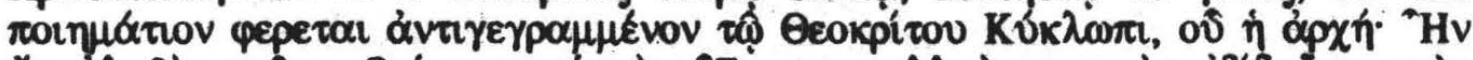

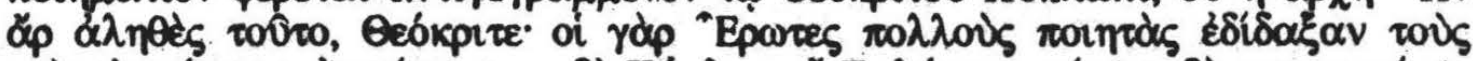

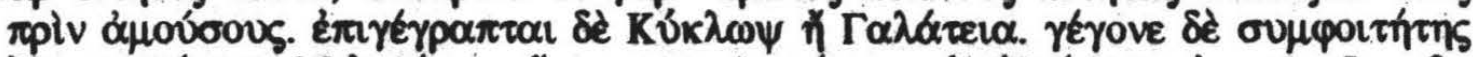

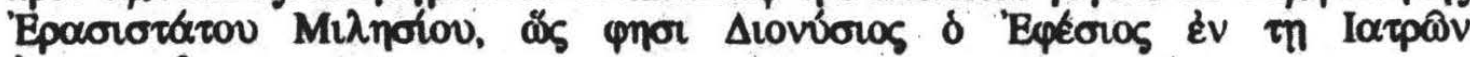
òvorpoupin.

2. Filoxeno de Citerea (436/5-380/9 a. C.) es un poeta ditirámbico que compuso la obra titulada Galatea, El Cielope o Galatee o ol Cielope, luego de huir de las canteras donde habla sido confinado por Dionisio I de Siracusa cuando intentó seducir a su amante, Galatea, según lo transmite Ateneo I, 6, e:

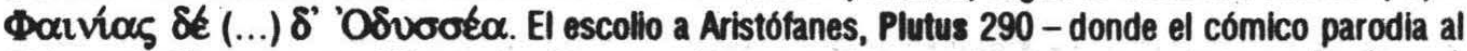

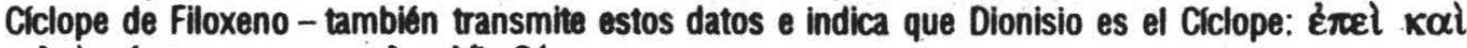

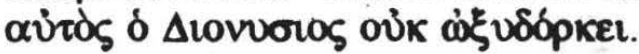


la epistola poética dirigida a Niciais ${ }^{3}$; él, como médico, conoceria los efectos de la acción de Eros en los hombres. Las Musas son presentadas como equivalente al

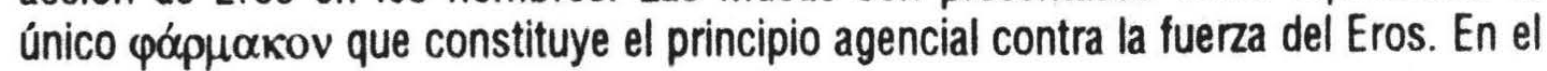

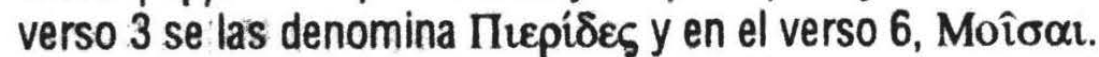

De este modo se alude a las Musas con el nombre propio que denota su relación con Tracia ${ }^{4}$, patria de Orfeo, hijo de Eagro y una Musa, Calíope o Polimnia según las distintas versiones del mito sobre su genealogía. La estructura sémica profunda de "Piérides" apunta al referente del músico, poeta y cantor por excelencia. La aparición de este nombre es funcional en el Idilio en tanto que se relaciona semánticamente con la actividad que realiza Polifermo.

Dentro de la primeira parte del segmento mítico (vv. 7 a 18), en que el poeta ubica el episodio en el tiempo y el espacio y presenta la problemática del

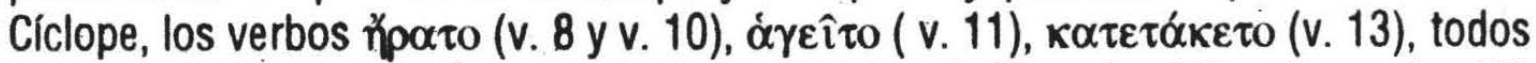

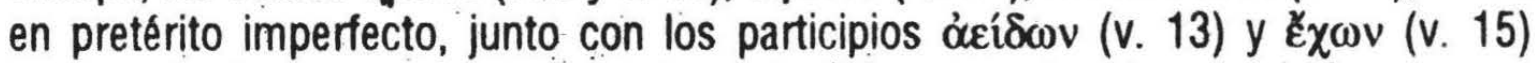
denotan la duración del amor por la ninfa. Por otro lado, el aoristo ev̂pe (v. 17) denota el carácter puntual, en el descubrimiento de la medicina, equivalente al aoristo $\pi \hat{\alpha} \xi \varepsilon(v$. 16) que predica sobre el dardo de la gran Cipris. Es decir que tanto el comienzo como el fin de la enfermedad, que se había desarrollado ávò xpóvov para el Cíclope, se producen por la acción divina -Cipris y Piérides- Ěv $\alpha$ xpóvov.

El discurso directo del Cíclope de los wv. 19-72 constituye el contenido del canto que termina con su enfermedad. El análisis de este discurso directo a partir de la disposición de sus elementos constitutivos, desde la perspectiva retórica, permite inferir el desarrollo del proceso mental de la figura mítica que evoluciona desde la enfermedad a la curación por la palabra. El punto de partida para este análisis es la definición de discurso como "el conjunto de estrategias de un orador que se dirige a un auditorio con vistas a modificar el juicio de este auditorio acerca de una situactión o acerca de un objeto" 5 . La distribución de los componentes, de acuerdo

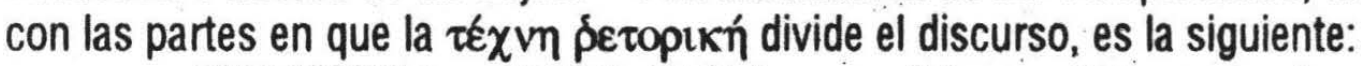

EXORDIUM (w. 19-24): El CIclope se dirige explícitamente al receptor de

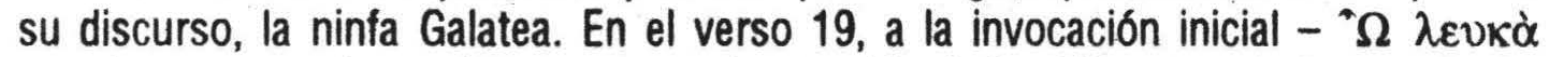
$\Gamma \alpha \lambda \alpha \alpha_{\varepsilon} \alpha \alpha-$ con la que intenta captar la atención de la ninfa, sigue la interrogación

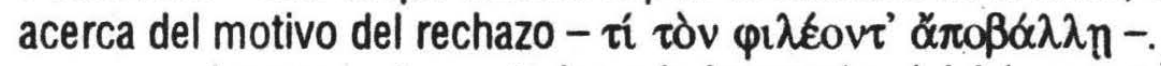

La pregunta posterior a la invocacion inicial es seguida por los atributos

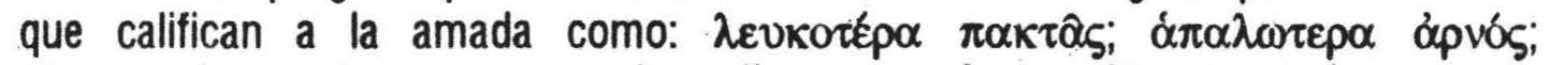

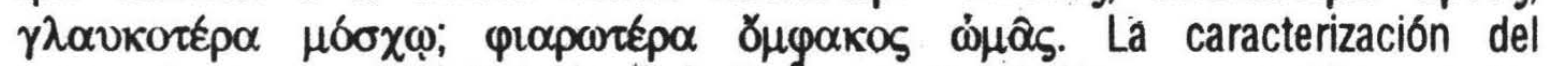
personaje, que es original de Teócrito ${ }^{6}$, resulta de la comparación con los elementos del mundo bucólico al que pertenece el Cíclope y tienen la función de

3. Cf. Rossi L.E., "L ? di Teocrito: epistola narrativa ed epillio", Studl Cataudella II, Univ. de Catania, (1972), p. 279

4. "Existían dos grupos principales de Musas: las de Tracia, de "Pieria", y las de Beocia, a las que se ubicaba en las laderas del Helicón. Las primeras, vecinas del Olimpo, son llamadas con frecuencia, en poesía "las Pierides". Guardan relación con el mito de Orfeo y el culto a Dioniso, que habla logrado gran importancia en Tracia. Las Musas del Hellcón son colocadas bajo la dependencla directa de Apolo. EI dirige sus cantos en torno a la fuente de Hipocrene." (Grimal, Diccionario de mitologla Griega v Romana, Barcelona, Paidós, 1986, s.v. "Musas".)

5. Cf. Vignaux Georges, La argumentación, ensayo de logica discursiva, Bs. As., Hachette, 1986, p.30.

6 . Cf. Poetae Lyricl Graeci, ed. Bergk, Lipsiae, 1880, p. 993. 
lograr una recepción benevolente de la ninfa, antes de continuar con la pregunta sobre el por qué ella se aproxima mientras él duerme y huye, indiferente a su sufrimiento, cuando se despierta. De acuerdo con esto se deduce que Galatea abandona el mar mientras él duerme aunque no se indica en qué momento del día. $\mathrm{Ni}$ en éste ni en otro momento del discurso existen referencias a la existencia de un diálogo anterior entre ellos.

NARRATIO (wv.25-29): El Cíclope le explica cómo y cuándo se enamoró de ella: Galatea llegó a recoger flores de jacinto con Toosa, la madre de Polifemo. EI personaje de Toosa es una creación teocritea dado que no existen testimonios anteriores de algún episodio mitico donde participe (excepto por ser madre de Polifemo en Odisea I, $71^{7}$ ) o se describan sus características.

CONFIRMATIVo (vv. 30-71): Polifemo expone los argumentos con los cuales intenta persuadir a Galatea para que lo ame.

En la propositio (vv. 30-33) Polifemo, respondiéndose a sí mismo la pregunta formulada al comienzo del discurso, hace su propia descripción física, con una presentación objetiva de sus rasgos ${ }^{8}$. Frente a esto, una extensa enumeración de sus posesiones y la descripción del ámbito en que vive constituye la argumentatio, cuerpo de razones probatorias con las que se intenta por un lado, equilibrar el efecto negativo de la descripción anterior $y$, por otro, debilitar argumentos supuestos como hipótesis:

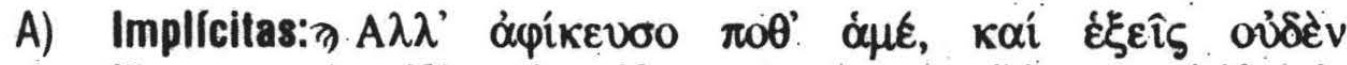
Ė $\lambda \alpha \sigma \sigma o v$. (v. 42); aclaración contra una posible suposición de Galatea en el sentido de que Polifemo no compartiría todo con ella.

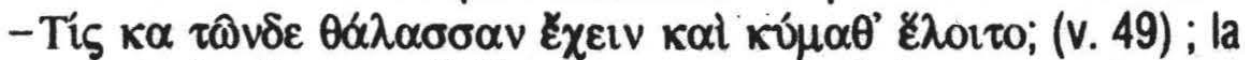
pregunta implica que Polifemo supone que Galatea se encuentra entre los que prefieren las cosas de la tierra a las del mar.

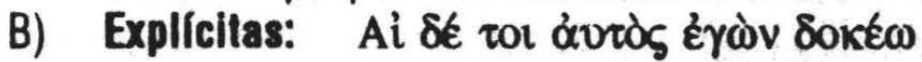

$\lambda \alpha \sigma$ torepos $\hat{\eta} \mu \varepsilon v$ (v. 50)

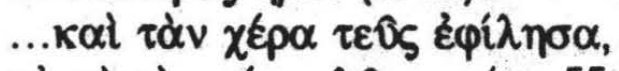

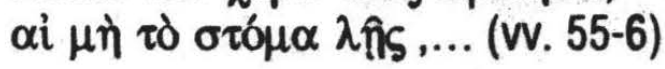

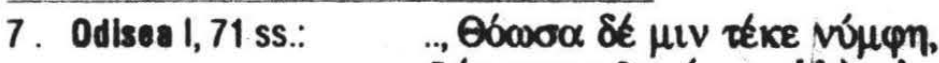

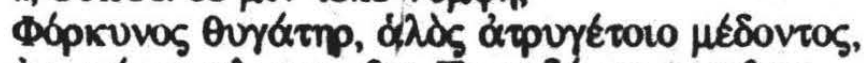

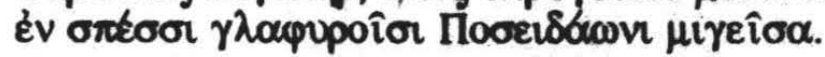

8. El poeta califica los sustantivos con adjetivos que no denotan compromiso afectivo, a diferencia del valor subjetivo que adquieren en el texto homerico, donde reflejan el punto de vista de Odiseo; el ojo y la ceja son los elementos en que coinciden ambas descripciones:

Odisea IX

Bopiss yóryos (v. 257)

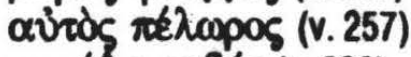
$\mu \varepsilon \gamma d \lambda^{\prime} \eta \eta$ vnoúg (v. 296)

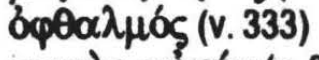
$\pi \times x v_{5} \alpha v x \eta v v(v .372)$

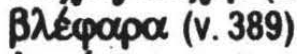
oxpúes (v. 389) $\gamma \lambda \hat{n} \cup \eta$ (v. 390)
Idillo XI

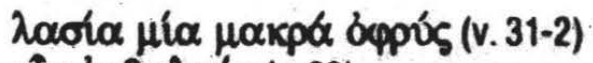

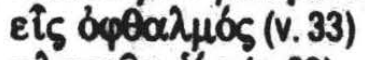

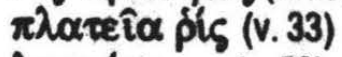
$\lambda$ ocíorepos (V. 50) $\lambda \eta \pi \tau \sigma \delta$ (v. 69) 
Esta parte del discurso de Polifemo presenta en forma indirecta la afición a la música del grupo social al que pertenece (v. 38). Los Ciclopes, como pastores, tocan la siringa, instrumento de origen divino que es el atributo esencial de Pan y que establece la jerarquía del personaje - que declara ser el que mejor la toca dentro del mundo bucólico.

Hacia el final de esta parte (vv. 63-66) y a modo de rogatio, el discurso incluye una expresión desiderativa para que Galatea abandone su mundo y comparta con él las actividades pastoriles.

DIGRESSIO (vv.67-71): Mediante el procedimiento de la amplificatio, Polifemo hace extensiva la causa de su estado emocional a las acciones de su madre, a partir de una apelación indirecta y del único reproche que contiene el discurso.

El núcleo sémico del nombre propio @ówo $\alpha$ se relaciona con el del adjetivo Ooós, que en una de sus valencias significa "agudo". En la estructura superficial de la composición se explicita que su silencio e indiferencia frente al sufrimiento de su hijo provocan en él un gran dolor. Frente a esto, el poeta, a través del discurso del Cíclope, presenta de manera implicita una alianza entre ella y Galatea y, en este sentido, el reproche se hace extensivo también a la ninfa.

CONCLUSIO (v. 72): De manera abrupta aparece en un sólo hexámetro la marca de finalización del discurso. El Cíclope se dirige a si mismo y resume todo 10 dicho hasta el momento, calificándolo como desvaríos.

El discurso directo del Ciclope de los w.73-79 manifiesta el resultado del discurso directo de los vv.19-72, con finalidad persuasiva, analizado hasta aquil, a partir de las pautas de la retórica. El Cíclope, quien ha constituido el único auditorio material de su propio discurso, y no Galatea, incluso en este momento ausente ${ }^{9}$, ha modificado su juicio.

Estos versos muestran un rasgo original del personaje teocriteo: Polifemo se observa a si mismo y se declara equivocado en cuanto a sus anteriores deseos. El personaje se presenta desdoblado y capaz de juzgarse a sI mismo, reflexionando sobre las cosas que son convenientes de acuerdo con lo que él hace, tiene y es.

En los versos 80-81, con que finaliza el Idilio el poeta, desde la dimensión histórica de la creación poética, cierra el episodio desarrollado en la dimensión del pasado mítico. El "oürcw" denota el carácter ejemplar que adquiere el segmento mítico para la epistola poética.

\section{CONCLUSión}

En Idilio plasma el discurso emitido por una mente en proceso de cambio.

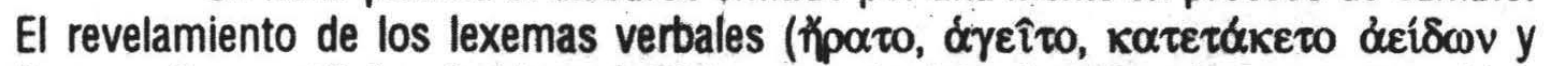
$\varepsilon \chi \omega v ; \varepsilon \hat{p} \varepsilon, \pi \hat{\alpha} \xi \varepsilon)$ referidos al Ciclope en la introducción al segmento mítico permite reconstruir el proceso por el que evoluciona desde la enfermedad hasta el

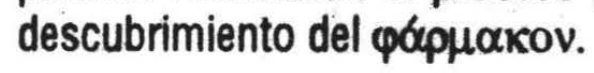

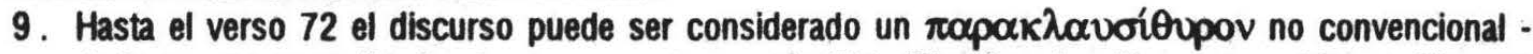
dado que no se realiza frente a una puerta cerrada H.V., "The Paraclausithyron as a Literary Theme", NPh XLI-4 (1920). 
Este discurso tiene la finalidad inicial de persuadir a Galatea (Exordium). La presencia de siringa funciona como marca de anticipatio del resultado: Siringa, dentro de la obra de Teócrito tiene, entre otras, la valencia de amor no realizado 10 . El análisis de los diferentes planos del discurso permite identificar la causa del rechazo de Galatea: lo único que se presenta como deseado por ella son las hojas color jacinto (NARRATIO) diferente de todo lo que Polifemo le ofrece (CONFIRMATIO), pero él, a lo largo de su discurso, parece no comprenderlo. El poeta enumera los dones ofrecidos sin que se manifieste en las palabras del Cíclope si alguno de ellos es realmente valioso para la Ninfa.

Teócrito, a través de las palabras de Polifemo caracteriza y transforma en personaje actante a la figura mítica de Galatea de la tradición anterior a él. El Cíclope parece incapaz de describir el cuerpo y el rostro de Galatea en detalle así como lo hace consigo mismo. A través de sus palabras únicamente se puede afirmar como verdadero que ella es blanca y brillante, una figura luminosa, él, en cambio, es alguien "en la tierra".

La ascendencia del Cíclope, engendrado por divinidades marinas, es relevante para explicar su amor por la Ninfa. Ésta simboliza el ámbito marino al que pertenecen sus antepasados y por el cual aún se siente atraído. El Cíclope a lo largo de su discurso, en el que se escucha a sí mismo decir cómo es, qué podría llegar a soportar, en lugar de persuadir se persuade a si mismo; ha recorrido el camino para alcanzar la $\alpha$ vo $\gamma$ vópiors en el autoconocimiento. Sus últimas palabras constituyen la muestra externa de la curación en tanto denotan su aprehensión de la esencia:

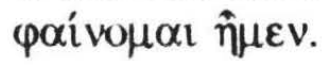

\section{Bibliografia}

\section{Ediciones y Escolios:}

Theocritus, edited with a Translation and Commentary, Gow A.S.F. ed., Cambridge, Univ., Press, 1952, 2 vols. Ed. bilingüe.

Bucoliques Grecs, Legrand Ph. ed., París, Les Belles Lettres, 1925, 2 vols. Ed. bilingüe.

DÜBNER. Scholia in Theocritum Parisiis, Editore Ambrosio Firmin - Didot, 1878.

Sobre Retorica:

ARISTÓTELLS. Retórica, Madrid, Insitutos de Estudios Políticos, 1971. Ed. bilingüe.

BARTHES, R. Investigaciones retóricas I, Barcelona, Ediciones Buenos Aires, 1982.

VIGNAUX, G. La argumentación, ensayo de Iógica discursiva, Bs. As., Hachette, 1986.

Sobre El "Idilio XI":

Poetae Lyrici Graeci, ed. Bergk, Lipsiae, 1880.

ALSINA, J. "Nota a Téccrito (XI 13)", Emérita XXXII, 1964.

BARIGAZZI, A. "Una presunta aporia nel c. 11 di Teocrito", Hermes 103-2, 1975.

10. Cf. análisis de La Siringa de Teócrito realizado en Los Idilios de Teócrito, seminario dictado por Lic. Elena Huber, 1987. (Inédito) 